\title{
Influence of Grazing Intensity on Soil Properties and Shaping Herbaceous Plant Communities in Semi-Arid Dambo Wetlands of Zimbabwe
}

\author{
E. Dahwa ${ }^{1 *}$, C. P. Mudzengi ${ }^{1}$, T. Hungwe ${ }^{2}$, M. D. Shoko ${ }^{2}$, X. Poshiwa ${ }^{3}$, S. Kativu ${ }^{4}$, C. Murungweni $^{5}$ \\ ${ }^{1}$ Department of Research and Specialist Services, Makoholi Research Institute, Masvingo, Zimbabwe; ${ }^{2}$ Faculty of Agricultural Sci- \\ ences, Great Zimbabwe University, Masvingo, Zimbabwe; ${ }^{3}$ Marondera College of Agricultural Sciences, University of Zimbabwe, \\ Marondera, Zimbabwe; ${ }^{4}$ Department of Biological Sciences, University of Zimbabwe, Harare, Zimbabwe; ${ }^{5}$ Department of Animal \\ Production and Technology, Chinhoyi University of Technology, Chinhoyi, Zimbabwe. \\ Email: *edahwa@yahoo.co.uk
}

Received April $9^{\text {th }}, 2013$; revised May $12^{\text {th }}, 2013$; accepted June $17^{\text {th }}, 2013$

Copyright (C 2013 E. Dahwa et al. This is an open access article distributed under the Creative Commons Attribution License, which permits unrestricted use, distribution, and reproduction in any medium, provided the original work is properly cited.

\begin{abstract}
Key issues of concern regarding the environmental impacts of livestock on grazing land are their effects on soil, water quality, and biodiversity. This study was carried out to determine how grazing intensity influences soil physical and chemical properties and occurrence of herbaceous plant species in dambo wetlands. Three categories of grazing intensity were selected from communal, small scale commercial and large scale commercial land. Dambos from the large scale commercial land functioned as the control. Data analysis included ANOVA and multivariate tests from CANOCO. There were significantly negative changes to soil nutrient status in communal dambos though with a higher number of rare taxa. Sodium, phosphorous, $\mathrm{pH}$ and infiltration rate were significant determinants of plant species occurrence. Overgrazing is threatening the productivity, stability, and ecological functioning of dambo soils in communal Zimbabwe. These dambos also require special conservation and management priorities as they contain a large number of rare plant species.
\end{abstract}

Keywords: Dambo Wetlands; Grazing; Soil Nutrients

\section{Introduction}

Key issues of concern regarding the environmental impacts of livestock on both public and private grazing lands are their effects on soil, water quality, riparian areas, and biodiversity [1]. The direct effects of livestock grazing on ecosystems are well known and include reduction in plant biomass, trampling of plants, including below ground parts and soil, nutrient inputs and bacterial contamination from dung and urine, introduction and dispersal of seeds and other propagules [1-4]. Properly managed grazing lands provide positive environmental benefits, including the provision of clean water supplies, the capacity to sequester atmospheric carbon (C), and the potential to maintain biodiversity [1].

Although many wetlands in the past have been degraded or destroyed as a result of inappropriate land use

${ }^{*}$ Corresponding author. or development pressures, more recently they have become the focus of intense conservation interest [5], particularly since the establishment in 1971 of the Convention on Wetlands of International Importance especially as Waterfowl Habitat (the "Ramsar Convention”). This convention promotes sustainable use of wetlands and provides a framework for the conservation of more than 1600 wetlands that have been nominated as internationally important on the basis of their ecological, botanical, zoological, limnological or hydrological values [6].

Dambo wetland is a small-scale environmental resource which is widespread in Africa's tropical plateau savannas [7]. The main area of dambo occurrence is located in Southern and Central Africa, with sporadic occurrence in central West and north Central Africa, south of the Sahara $[8,9]$. With the exception of a typically narrow $(<150 \mathrm{~km})$ humid zone around the southern and eastern margins of the subcontinent, the interior and western 
margin are mostly drylands, with annual potential evaporation greatly exceeding annual precipitation [5]. Across southern Africa, wetlands (including more than 20 Ramsar listed sites) can be found in a variety of coastal and inland settings [5] but the emphasis here is on those wetlands that occur within the dryland interior. In Zimbabwe, wetlands are estimated to cover some 1.28 million hectares of the country's land surface. Some $20 \%$ of this wetland area lies in communal areas [10].

Dambo wetlands are highly sensitive to grazing pressure. As such, they are considered as useful environmental indicators of environmental pressures [8,11]. Land pressure has forced communities to concentrate on land and water availability irregardless of the state of these environmental resources [12].

A number of studies have been carried out on the geography and hydrology of dambos. These have focussed on social and agricultural importance of dambos in Zimbabwe [8,13-15]. However, only a few make any reference to important factors shaping the plant communities in wetlands, particularly in the dry ecological Natural Region (NR) of Zimbabwe [16].

Scientific interest in wetlands has also increased rapidly over the last few decades $[3,7,14,17,18]$, largely in response to growing pressures for increased data to inform management decisions regarding conservation, rehabilitation or artificial construction of wetlands, and particularly in view of the potential adjustments that may result from global climate changes [5]. Despite the increased interest in research, there is still lack of scientific understanding especially of wetlands in the world's extensive drylands [5], a collective term that includes subhumid, semiarid, arid and hyperarid regions and incurporates almost $50 \%$ of the global land area and nearly $20 \%$ of the global population [6].

The objective of this study was to determine the extent at which grazing influences soil nutrient dynamics, interaction with plant community and how these influence occurrence of herbaceous plant species in wetlands. Also to determine if communal dambo wetlands are worthwhile to conserve. In order to make valid comparisons, dambos in the same catchment area under different management were compared. It is hypothesized that grazing in dambos results in changes to important soil physical and chemical properties which influence occurrence of plant species.

\section{Materials and Methods}

\subsection{Description of the Experimental Site}

The study area is located to the north of Masvingo town in Zimbabwe. The area falls within Natural Region IV (NR4) of the Zimbabwean ecological classification sys- tem [19]. Altitude is $1204 \mathrm{~m}$ above sea level on latitude $19^{\circ} 50^{\prime} \mathrm{S}$ and longitude $30^{\circ} 46^{\prime} \mathrm{E}$. NR4 is suitable for extensive farming, and receives an annual rainfall of 450 to $650 \mathrm{~mm}$. Mean maximum temperature during summer is about $28^{\circ} \mathrm{C}$, and the minimum temperature during winter is about $6^{\circ} \mathrm{C}$. It is characterised by sandy soils with low organic matter and humus content, and consequently low fertility. Farming activities in the area are considered risky because of highly variable rainfall [20].

\subsection{Dambo Wetland Selection}

Three categories of dambos from contrasting land use history were identified based on frequency and severity of defoliation. Two sites per category were selected and were the ungrazed (UG), moderately grazed (MG) and continuously grazed (CG). The three categories were selected from communal, small scale commercial and large scale commercial land respectively. Ungrazed sites functioned as the control treatment. Aerial photographic maps and a Global Positioning Satellite (GPS) altitude-measuring unit were used as aids for selection. Using mileage, a motorbike was run along and across dambos to estimate their varying sizes.

\subsection{Vegetation Sampling}

At least three transects measuring $100 \mathrm{~m}$ or less were laid in each dambo, this depending on size of the dambo sampled (dambos ranged in size from 0.9 - $4.5 \mathrm{ha}$ ). All transects were laid perpendicular to the general dambo hydrologic gradient to capture any variations due to moisture gradient [3]. Transects were also laid at least $30 \mathrm{~m}$ from roads to minimise border effects. Within each dambo, vegetation was sampled from $0.5 \mathrm{~m}^{2}$ quadrats systematically placed $10 \mathrm{~m}$ intervals along transects [21]. Sampling was started at the center and then transversing to the edge of the dambos. In each dambo, at least 30 subsamples were obtained. Edges of dambos were determined by sampling until the vegetation cover was $>90 \%$ pasture grass cover [22]. A GPS unit was used to measure altitude and coordinate points within each sampling unit (quadrat). Variables recorded from each quadrat to determine species composition were: name of species (nomenclature followed [23]), erosion estimates (scale of 1 - 10, were 1 is no erosion while 10 is badly eroded).

\subsection{Soil Sampling}

For soil sampling, subsamples were collected along transects from the center of every third $0.5 \mathrm{~m}^{2}$ quadrat. A minimum of 10 soil subsamples were collected from each dambo. A soil auger was used to collect soil at a depth of top $15 \mathrm{~cm}$. Upon return from field, subsamples were air dried under shade for a few days and then stored 
in plastic bags for later analysis. Due to homogeneity of vegetation and soils within dambos, fewer subsamples were collected for analysis [24]. Samples were then analysed for bulk density, $\mathrm{Na}, \mathrm{P}$ and $\mathrm{pH}\left(\mathrm{CaCl}_{2}\right)$.

\subsection{Water Infiltration Rate}

A double ring infiltrometer was used to measure water infiltration rate. The instrument was assembled as outlined in the product manual [25]. The instrument was placed at every third quadrat (where a soil sample was taken). This also yielded a minimum of 10 subsamples from each dambo. The rate of infiltration was determined as the amount of water per surface area and time $(\mathrm{cm} / \mathrm{min})$ that penetrated the soil. Water percolation is initially fast, but reduces gradually to a constant value, and this is the infiltration rate [25].

\subsection{Data Analysis}

One way ANOVA from SPSS ver. 13 was used to test for significant differences in soil physical and chemical properties and also in vegetation attributes. Least Significance Difference was used to separate the means. Species data were converted to a presence absence matrix consisting of six dambos by 65 herbaceous plant species. Detrended correspondence analysis (DCA) and hierarchical canonical correspondence analysis from CANOCO ver. 4 were used to assess multivariate relationships between vegetation and environmental data and compared vegetation composition among different dambos. Monte Carlo tests were done to test for significance of soil properties in explaining the observed patterns. Multivariate methods provide a means to structure the data by separating systematic variation from noise $[26,27]$.

\section{Results}

\subsection{Soil Physico-Chemical Properties}

Soil physical (Table 1) and chemical (Figures 1 and 2) properties varied significantly across the three grazing categories. Phosphorous, sodium and water infiltration were significantly higher under moderate grazing when compared to ungrazed and overgrazed sites. Bulk density, erosion and $\mathrm{pH}$ were significantly higher under continuous grazing while lower under both moderate and ungrazed.

\subsection{Plant Species Relationships with Environmental Variables}

The Eigenvalues for axis 1 (horizontally) and axes 2 (vertically) are 0.16 and 0.12 respectively and they explained a total variance of $64.1 \%$ of the observed variation (Table 2). The first synthetic gradient (axis 1) showed a significantly positive correlation of plants with $\mathrm{Na}$ and $\mathrm{pH}(P<0.05)$. The second synthetic gradient showed a positive correlation of plants with water infiltration rate and bulk density while negatively with phosphorus and erosion (Figure 3). Monte Carlo tests showed significance of all axes in predicting the observed differences in plant species occurrence $(P<0.05)$.

\subsection{Plant Species Occurrence across Different Dambos}

The ordination diagram (Figure 4) is a cluster of species produced from HCCA. Results from the plot shows three clusters based on plant species presence or absence. Results indicate differences in species occurrence across sites. Sites with same species are indicated by forming a cluster. Continuously grazed sites had a significantly higher number of rare plant species $(P<0.05)$.

\section{Discussion and Conclusion}

\subsection{Influence of Grazing on Environmental Variables}

While a number of studies have investigated the effects of livestock on soil quality in a range of ecosystem types, very few have been conducted in dambo wetlands [28]. Other studies have also found that in old embanked salty marshes, trampling altered the soil structure (to lamellar structure indicative of compaction) reducing soil infiltration and preventing salt from being leached from the soil [28].

The impact on soils was reflected by differences in soil properties between the differently grazed dambos. Infiltration rates were significantly lower in continuously grazed sites as compared to moderately and ungrazed sites. Continuously grazed sites had significantly higher soil bulk density and higher erosion estimates as compared to other sites. Trampling and compaction of soils by livestock decreases water infiltration and increase runoff hence exposing the soil to erosion hazard [14]. Ex-

Table 1. Mean soil physical properties in dambos subjected to different grazing intensities.

\begin{tabular}{cccc}
\hline Variable & Ungrazed & Grazing intensity Moderate & Continuous \\
\hline Basic Infil. rate $(\mathrm{cm} / \mathrm{min})$ & $0.53^{\mathrm{c}}$ & $0.78^{\mathrm{a}}$ & $0.24^{\mathrm{b}}$ \\
Erosion (estimate: $1-10)$ & $0.85^{\mathrm{c}}$ & $1.72^{\mathrm{a}}$ & $1.76^{\mathrm{b}}$ \\
Bulk density $\left(\mathrm{g} / \mathrm{cm}^{3}\right)$ & $1.10^{\mathrm{a}}$ & $1.10^{\mathrm{a}}$ & $1.22^{\mathrm{b}}$ \\
\hline
\end{tabular}

Means in rows with different superscripts are significantly different $(\mathrm{P}<0.05)$. 


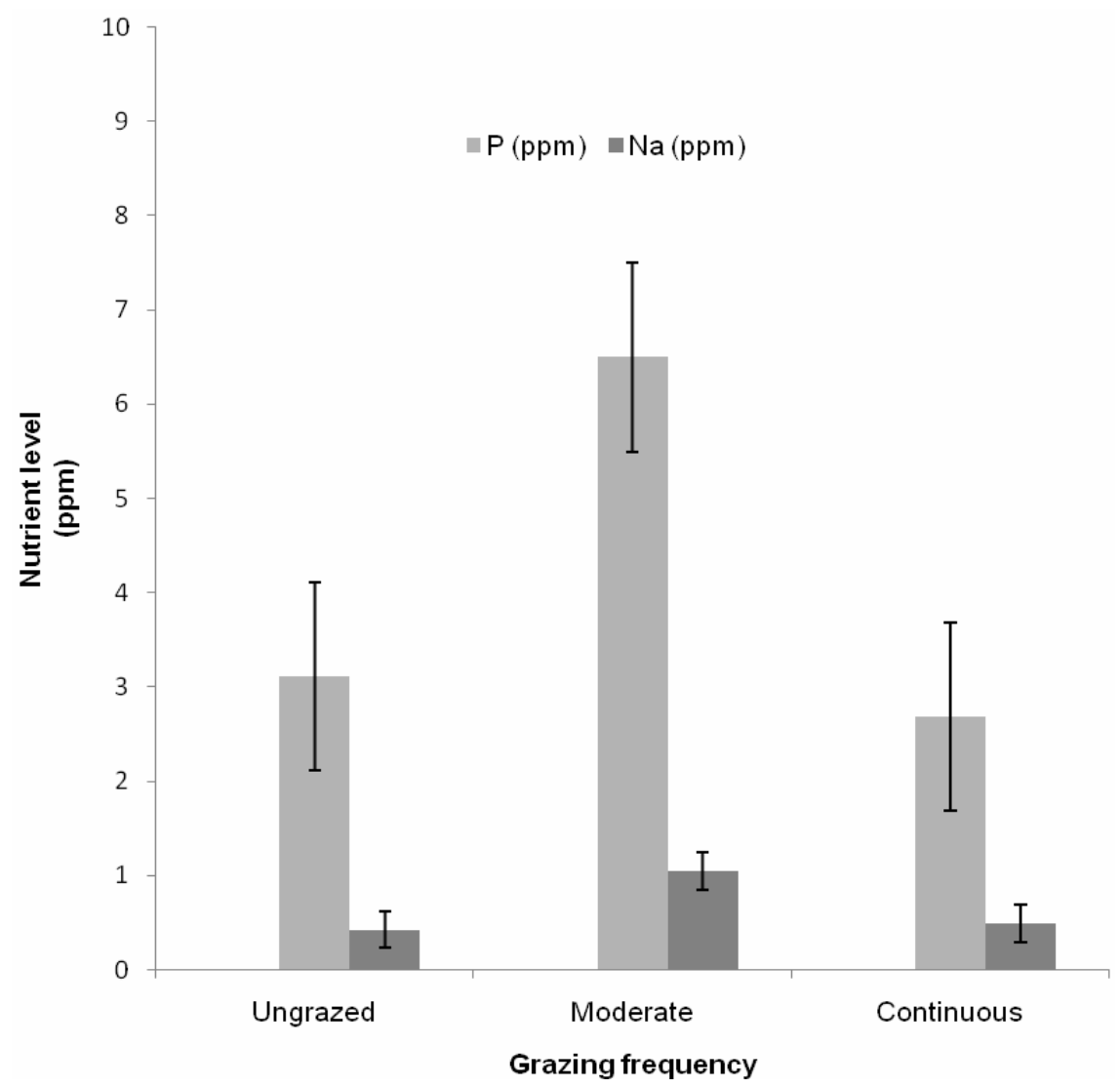

Figure 1. Mean soil phosphorus and sodium levels at sites under different grazing intensities. Values presented are \pm standard deviation.

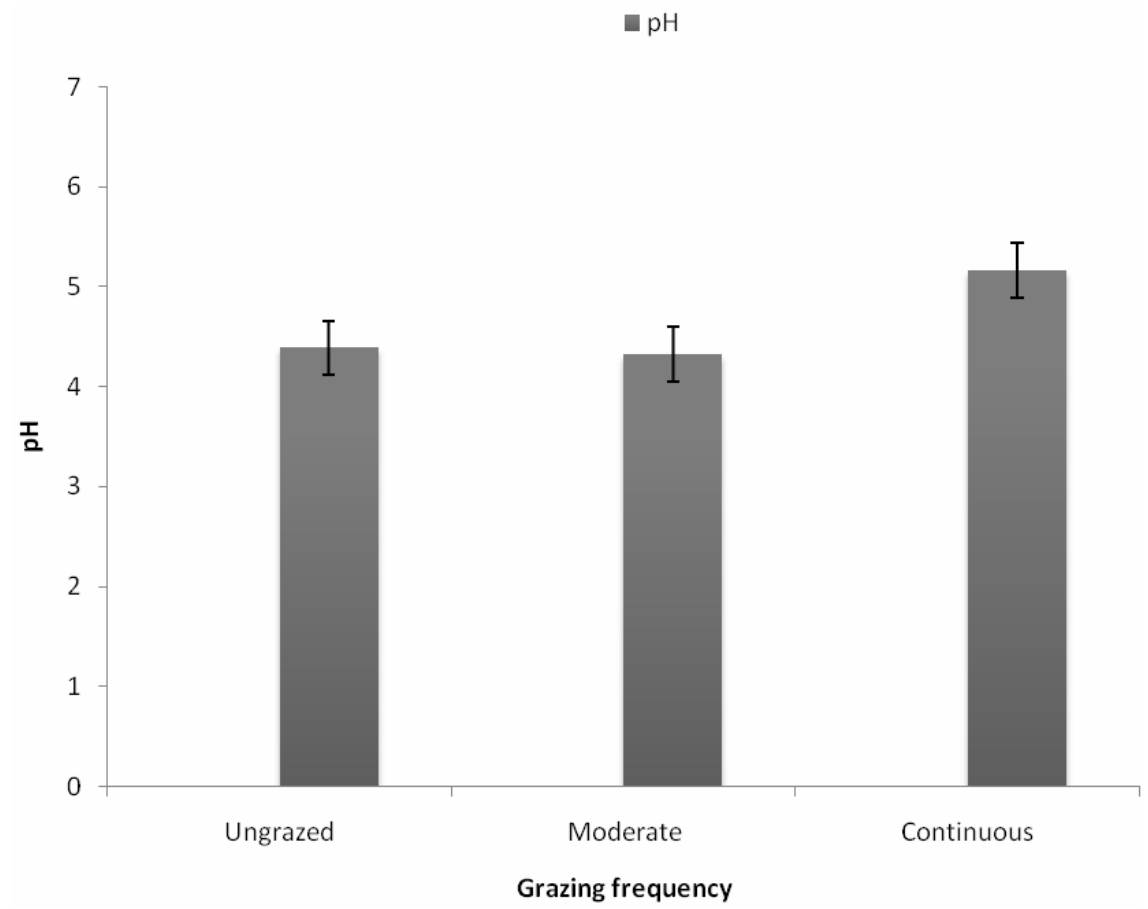

Figure 2. Mean soil pH levels across dambo sites subjected to different grazing management regimes. Values presented are \pm standard deviation. 
Table 2. Summary of eigenvalues for species environment correlations.

\begin{tabular}{lccccc}
\hline \multicolumn{1}{c}{ Axes } & $\mathbf{1}$ & $\mathbf{2}$ & $\mathbf{3}$ & $\mathbf{4}$ & Total inertia \\
\hline Eigen values & 0.16 & 0.12 & 0.08 & 0.56 & 9.90 \\
$\begin{array}{l}\text { Species-environment correlations } \\
\text { Cumulative \% variance }\end{array}$ & 0.62 & 0.54 & 0.43 & 0.00 & \\
of species data: & 1.40 & 2.40 & 3.00 & 7.8 \\
of species-environment relation: & 37.0 & 64.10 & 81.80 & 81.90
\end{tabular}

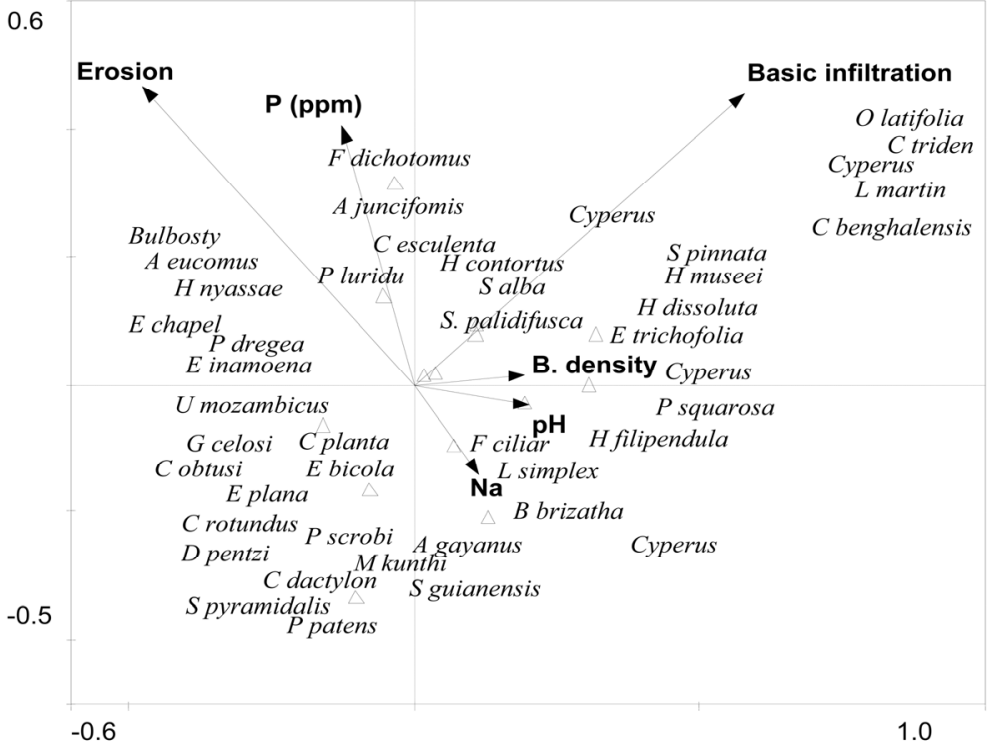

Figure 3. HCCA biplot indicates how environmental variables influence the occurrence of herbaceous plant species in dambos.

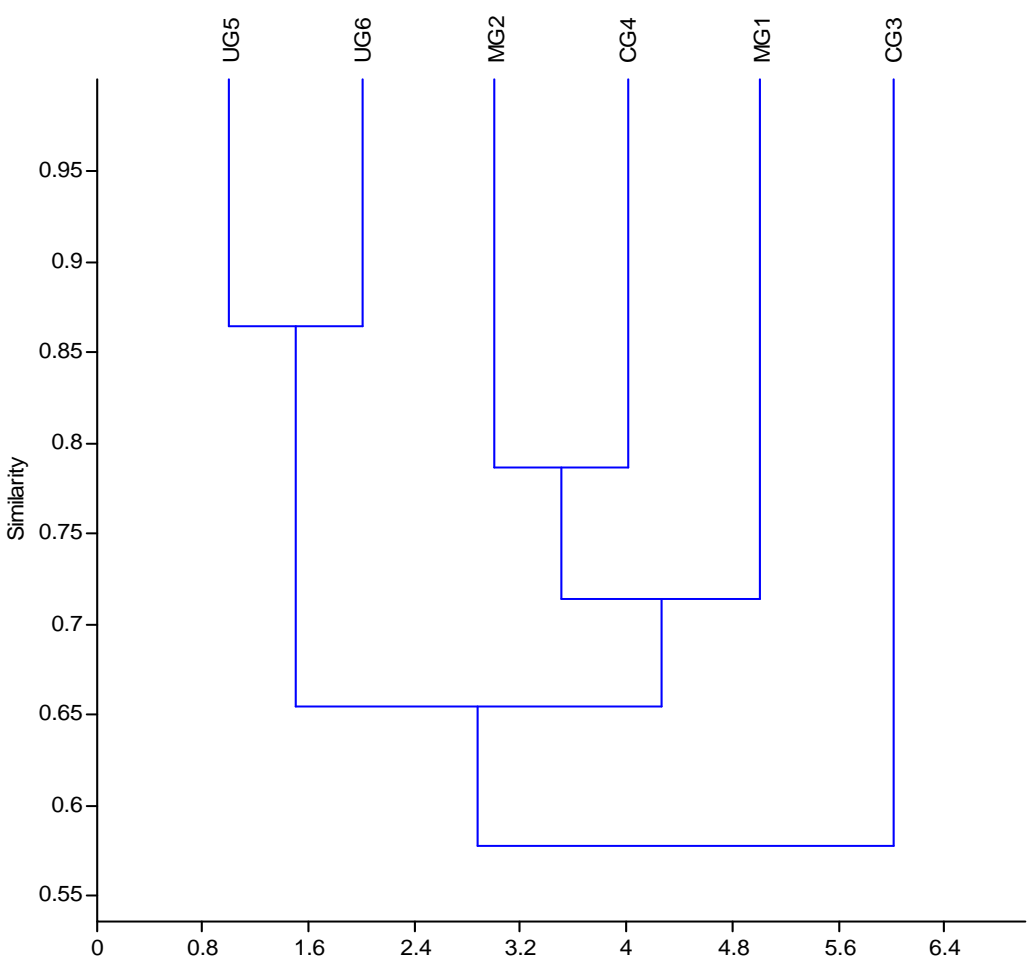

Figure 4. HCCA cluster based on species presence/absence in dambo under different grazing intensities. 
cessive compaction has negative consequences on plant growth [29]. Grazing increases bulk density or decreases soil porosity [1,30,31]. Even though soil changes can result from excessive compaction during grazing, studies also have shown that natural processes such as soil wetting and drying cycles and livestock can affect soil quality through compaction, erosion, and changes in the plant community [3,4]. Soil compaction by livestock is comparable to farm machinery and is most severe in the top 5 centimetres of the soil but can extend as deep as $30 \mathrm{~cm}$ [29]. The degree of compaction depends on soil moisture levels, type of soil and stocking densities. Maximum compaction occurs at soil moisture levels of between $20 \%$ to $30 \%$ moisture-holding capacity (depending on soil type) and field capacity, as well as at high stocking densities [1].

Dambos in Zimuto have been continuously grazed for over 6 decades with subsequent increase in livestock numbers over the years. Reduced water infiltration rates under continuous grazing suggest soil compaction and reduced pore size of soil. Soil deterioration and erosion is high under continuous grazing. This is evidenced by presence of grass species tolerant to heavy grazing like Sporobolus pyrimidalis, Cynodon dactylon and several Eragrostis species. We suggest that soil deterioration could be limited by reducing stocking intensities during dry periods in the communal areas. Similar results have been reported where water filtration rates on silty clay and silty clay loam soils were 2.5 times greater in an area grazed at 1.35 acres/AUM compared to an area grazed at 3.25 acres/AUM [1,32]. After 22 years of grazing at this intensity, not only had species composition altered but soil properties had been changed as well.

Continuously grazed sites had significantly higher soil $\mathrm{pH}$ values (Figure 2) as compared to the other sites. This possibly can be explained by the fact that desiccation is higher. As the water evaporates, it leaves the soil with a higher concentration of salts hence a slightly higher $\mathrm{pH}$ value as compared to the other sites. Generally dambos have increased agricultural fertility due to higher concentrations of potassium, phosphate and organic matter, and greater cation exchange capacities [7]. Dambo soil characteristics reflect the greater biomass production, lower decomposition rate and the inwash of ions from upslope [7]. In line with our findings, it was reported that calcareous fens had lower $\mathrm{pH}$ and higher nitrate $\left(\mathrm{NO}_{3}\right)$ levels, with no differences in ammonium between grazed and ungrazed sites [33]. These results suggest that manure inputs were being nitrified and that although the fens were accumulating nitrogen, there may be some resilience to increase in potentially toxic ammoniacal nitrogen levels.

\subsection{Species-Environmental Relationships}

Our results indicated strong vegetation-explanatory variable relationships in all studied dambo sites. A detrended correspondence analysis (DCA) was first carried out to ascertain on the behaviour of data [27]. Results of DCA indicated that most of the species behaved approximately unimoidal along environmental gradients as indicated by the length of maximum gradient which was greater than 4Sd [34]. Inorder to define the links between species and the environment, hierarchal canonical correspondence analysis (hCCA) followed.

The analysis of species environment relationships and the identification of indicator species are traditional activities in ecology [35]. Knowing how human activity influences the fascinating diversity of biological communities raises much interest in people. However, this very diversity creates problems for the statistical analysis of ecological observations [36]. This implies a large number of species and a large inherent variability. A set of community samples and associated environmental measurements typically yields an enormous amount of noisy data which is difficult to interpret.

By using hCCA, it has been shown that plant structuring and composition in the studied community are considerably influenced by individual effects of ecological factors. Sodium and $\mathrm{pH}$ were positively correlated with axis 1 (Figure 3) and as such are major gradients influencing the structuring and diversity of the plant communities. Other factors like infiltration rates, bulky density, phosphorous and erosion are linked to the second axis and are important as well. Any factors leading to changes in water filtration, $\mathrm{pH}$ and sodium levels in the dambo wetlands will lead to changes in herbaceous species composition and occurrence of these fragile ecosystems.

Weed species like Oxalis latifolia, C. triden and C. bangalensis occurred on well drained soil usually soils close to the top land. Soil moisture gradient could be important in determining or governing the occurrence of these plants. Any factors affecting the drainage conditions of wetlands e.g. infiltration rate will affect what species will occur there. The occurrence or abundance of a species along an environmental gradient often follows shelford's law of Tolerance [37]. Each species thrives best at a particular value (its optimum) and cannot survive when the value is either too low or too high. Each species occurrence is thus confined to a limited range, its niche. Species tend to separate their niche, partly so as to minimise competition. If the separation is strong, successive species replacements occur along environmental gradient. The composition of biotic communities thus changes along environmental gradients according to unimoidal functions [37]. 
Some individual factors may have a minor influence, for example the effects of erosion and litter cover and total species richness, but their interactions with each other or with other factors, such as litter accumulation, may have a substantial influence on total species diversity and composition. Consequently, knowledge about the role of individual factors only, and ignorance of their interactions, may lead to false predictions about community structure and function.

The cluster (Figure 4) indicates that communities of same ecological background are segregating based on species composition and soils. Plant species composition and structure can be altered indirectly through the modified soil environment and directly through trampling [29]. The overgrazed sites had a relatively higher number of rare plant species. This may indicate the need for higher priority for conservation in communal dambo wetlands.

\subsection{Importance of Interactions}

A number of biotic and abiotic factors have been proposed as determinants shaping plant species structure and diversity [38]. However, when considering the rates of species gain or loss in the community, most attention has been directed to the roles of disturbance, physical resources, species interactions and propagule availability. The failure to identify any single factor as the major determinant of species diversity on a more local scale suggests that interactions between several factors are often more important. There are significant strong correlations between sodium and $\mathrm{pH}$, and also between bulk density and $\mathrm{pH}$. The more factors that are involved in an experiment the more complex the possible interactions, and the more sophisticated the analytical techniques required to interpret them. Although a complexity of interactions between different factors has been assumed in plant community theory $[17,37,38]$, few experiments have combined more than two factors to test such effects.

\section{Conclusion}

Continuous grazing is threatening the productivity, stability, and ecological functioning of dambo wetlands in communal areas. There are deleterious changes to soil nutrients which are important vegetation determinants in the dambos. There are evident changes in species composition among differently grazed sites. Communal dambos are less fertile and have a higher number of rare taxa, hence requires special conservation and management priority. Debate over grazing needs to move beyond the simple dichotomy of whether it is good or bad. Evaluation of practical alternatives should be done through experimental studies.

\section{Acknowledgements}

The authors gratefully acknowledge the field assistance of Chiuta T., Mutata L., Muraza I., Madokudya A. Anthony Mapaura from the National Herbarium, Harare, helped with the identification of some plants and Mr. Mutsambiwa from the Soils and Chemistry Laboratory of the University of Zimbabwe carried out the soil analyses. Project went well with financial assistance from the Ministry of Agriculture mechanisation and Irrigation Development. We would like to thank Proffesor CHD Magadza for his input and comments earlier on.

\section{REFERENCES}

[1] CAST (Council for Agricultural Science and Technology), "Environmental Impacts of Livestock on US," Grazing Lands, Vol. 6, 2002.

[2] G. F. Hayes and K. D. Holl, "Cattle Grazing Impacts on Annual Forbs and Vegetation Composition of Mesic Grasslands in California,” Conservation Biology, Vol. 17, No. 6, 2003, pp. 1694-1702. http://dx.doi.org/10.1111/j.1523-1739.2003.00281.x

[3] W. M. Jones, L. H. Fraser and J. Curtis, "Plant Community Functional Shifts in Response to Livestock Grazing in Intermountain Depressional Wetlands in British Columbia, Canada,” Biological Conservation, Vol. 1, No. 144, 2010, pp. 511-517.

[4] J. T. Marty, "Effects of Cattle Grazing on Diversity in Ephemeral Wetlands," Conservation Biology, Vol. 16, 2004, pp. 1626-1632.

[5] S. Tooth and T. S. McCarthy, "Wetlands in Drylands: Geomorphological and Sedimentological Characteristics, with Emphasis on Examples from Southern Africa," Progress in Physical Geography, Vol. 31, No. 1, 2007, pp. 3-41. http://dx.doi.org/10.1177/0309133307073879

[6] SCBD (Secretariat of the Convention on Biological Diversity), "Global Biodiversity Outlook," SCBD, Montréal, Vol. 3, 2010.

[7] I. Scoones, "Wetlands in Drylands: Key Resources for Agricultural and Pastoral Production in Africa," Ambio, Vol. 8, No. 20, 1991, pp. 366-371.

[8] N. Roberts, "Dambos in Development of a Fragile Ecological Resource,” Journal of Biogeography, Vol. 15, No. 1, 1988, pp. 141-148 http://dx.doi.org/10.2307/2845054

[9] J. C. Von der Heyden, "The Hydrology and Hydrogeology of Dambos: A Review,” Progress in Physical Geography, Vol. 28, No. 4, 2004, pp. 1-21.

[10] M. Mharapara, M. D. Munema and R. Mkwanda, "Wetland Characterization and Classification for Sustainable Agricultural Development. FAO, Zimbabwe Country Paper Experiences on Wetland Characterisation, Classification, Management and Utilization for Agricultural Development in Zimbabwe: A Case for Wetland Research,” FAO, Vol. 1, No. 132, 1997.

[11] D. Limpitlaw and G. Rudigergens, "Dambo Mapping for Environmental Monitoring Using Landsat TM and SAR 
Imagery: Case Study in the Zambian Copperbelt,” International Journal of Remote Sensing, Vol. 27, No. 21, 2006, pp. 4839-4845.

http://dx.doi.org/10.1080/01431160600835846

[12] S. Mtetwa and C. F. Schutte, “An Interactive and Participative Approach to Water Quality Management in AgroRural Watersheds,” Water SA, No. 28, 2002.

[13] M. Bell and N. Roberts, "The Political Ecology of Dambo Soil and Water Resources in Zimbabwe," Transactions of the Institute of British Geographers, New Series, Vol. 16, No. 3, 1991, pp. 301-318. http://dx.doi.org/10.2307/622950

[14] A. Bullock and M. P. McCartney, "Wetland and River Flow Interactions in Zimbabwe. L'hydrologie Tropicale: géOscience et Outil Pour le Development," IAHS, No. 238, 1996.

[15] R. Whitlow, "A Review of Dambo Gullying in SouthCentral Africa,” XVI Department of Geography, University of Zimbabwe, Zambezia, 1989.

[16] J. M. Bullock, J. Franklin, M. J. Stevenson, J. Silvertown, S. Coulson, S. J. Gregory and R. Tofts, “A Plant Trait Analysis of Responses to Grazing in a Long Term Ex- periment,” Journal of Applied Ecology, Vol. 38, No. 2, 2001, pp. 253-267. http://dx.doi.org/10.1046/j.1365-2664.2001.00599.x

[17] P. A. Keddy, L. H. Fraser and T. A. Keogh, "Responses of 21 Wetland Species to Shortages of Light, Nitrogen and Phosphorus," Bulletin of the Geobotanical Institute, Vol. 67, 20011, pp. 3-25.

[18] P. N. Reeves and P. D. Champion, "Effects of Livestock Grazing on Wetlands," National Institute of Water and Atmospheric Research Ltd., No. EVW042732004, 2004.

[19] V. Vincent and R. G. Thomas, "An Agricultural Survey of Southern Rhodesia,” Agro-Ecological Survey, Vol. 1, 1961.

[20] T. Mutimukuru, G. D. Mudimu, S. Siziba, N. Harford and C. Garforth, "Demand Assessment Study of Resource Conserving Technologies in Chivi and Zimuto Communal Areas in Masvingo Province, Zimbabwe,” DFID, Natural Resources Systems, Masvingo, 2000.

[21] J. T. Curtis and R. P. McIntosh, "The Interrelations of Certain Analytic and Synthetic Phytosociological Characters,” Ecology, Vol. 31, No. 3, 1950, pp. 434-455. http://dx.doi.org/10.2307/1931497

[22] E. H. Boughton, A. Quintana, P. J. Bohlen, D. G. Jenkins and R. Pickert, "Land Use and Isolation Interact to Affect Wetland Plant Assemblages,” Ecogeography, Vol. 33, 2010, pp. 461-470.

[23] H. Wild, "A Rhodesian Botanical Dictionary of African and English Plant Names,” National Herbarium, Department of Research and Services, Ministry of Agriculture, Government printer, Salisbury, 1972.

[24] M. L. Amanda, R. G Glenn and T. F. H Allen, “Conceptual Hierarchical Modelling to Describe Wetland Plant Community Organization,” Wetlands, Vol. 30, No. 1, 2010, pp. 55-65. http://dx.doi.org/10.1007/s13157-009-0010-5

[25] Eijkelkamp, “The Double Ring Infiltrometer," Product Manual, 2nd Edition, 1983.

[26] H. G. Gauch, "Multivariate Analysis in Community Ecol- ogy,” Cambridge University Press, Cambridge Cambridgeshire and New York, 1982.

[27] K. McGarigal, S. Cushman and S. Stafford, "Multivariate Statistics for Wildlife and Ecology Research," SpringerVerlag, New York, 2000. http://dx.doi.org/10.1007/978-1-4612-1288-1

[28] R. R. Blank and T. Morgan, "Influence of Livestock Grazing, Floodplain Position and Time on Soil Nutrient Pools in a Sierra Nevada Montane Meadow,” Soil Science, Vol. 6, No. 75, 2010, pp. 293-302. http://dx.doi.org/10.1097/SS.0b013e3181e73c0f

[29] K. L. Greenwood and B. M. McKenzie, "Grazing Effects on Soil Physical Properties and the Consequences for Pastures: A Review,” Australian Journal of Experimental Agriculture, Vol. 8, No. 41, 20011, pp. 231-250.

[30] V. S. Baron, A. C. Dick, E. Mapfumo and S. S. Malhi, "Grazing Impacts on Soil Nitrogen and Phosphorus under Parkland Pastures,” Journal of Range Management, Vol. 54, No. 6, 2001, pp. 704-710. http://dx.doi.org/10.2307/4003675

[31] S. D. Warren, W. H. Blackburn and C. A. Jnr. Taylor, "Effects of Season and Stage of Rotation Cycle on Hydrologic Condition of Rangeland under Intensive Rotation Grazing,” Journal of Range Management, Vol. 6, No. 39, 1986, pp. 486-491. http://dx.doi.org/10.2307/3898754

[32] J. Kauffman and B. Krueger, "Livestock Grazing Effects on Soil Physical Properties,” Journal of Range Management, Vol. 5, No. 6867, 1984.

[33] D. Van Hoewyk, P. M. Groffman, E. Kiviat, G. Mihocko and G. Stevens, "Soil Nitrogen Dynamics in Organic and Mineral Soil Calcareous Wetlands in Eastern New York," Soil Science Society of America, Vol. 64, No. 6, 2000, pp. 2168-2173. http://dx.doi.org/10.2136/sssaj2000.6462168x

[34] T. C. J. F. Braak, "Canonical Correspondence Analysis: A New Eigenvector Technique for Multivariate Analy- sis,” Ecology, Vol. 5, No. 67, 1986, pp. 1167-1179. http://dx.doi.org/10.2307/1938672

[35] A. Petraglia and M. Tomaselli, "Ecological Profiles of Wetland Plant Species in the Northern Apennines (N. Italy)," Journal of Limnology, Vol. 62, No. 1, 2003, pp. 7178. http://dx.doi.org/10.4081/jlimnol.2003.71

[36] T. C. J. F. Braak and P. F. M. Verdonschot, "Canonical Correspondence Analysis and Related Multivariate Methods in Aquatic Ecology,” Aquatic Sciences, Vol. 6, No. 57, 1995, pp. 255-289. http://dx.doi.org/10.1007/BF00877430

[37] P. A. Keddy, "Effects of Competition from Shrubs on Herbaceous Wetland Plants: A Four Years Field Experiment," Canadian journal of Botany, Vol. 67, No. 3, 1989, pp. 708-716. http://dx.doi.org/10.1139/b89-094

[38] S. Xiong, M. E. Johansson, F. M. R. Hughes, A. Hayes, K. S. Richards and C. Nilsson, "Interactive Effects of Soil Moisture, Vegetation Canopy, Plant Litter and Seed Addition on Plant Diversity in a Wetland Community," Journal of Ecology, Vol. 91, No. 6, 2003, pp. 976-986. http://dx.doi.org/10.1046/j.1365-2745.2003.00827.x 